\title{
Correlation between postoperative pain and patient satisfaction
}

Carlos Noversa, Andreia Moura, Francisco Matias, Ana Valentim Centro Hospitalar e Universitário de Coimbra, Portugal

Most patients are expecting to experience postoperative pain and no significant relief with analgesia. ${ }^{1,2}$

Moderate to severe postoperative pain remains a clinical problem but most patients refer being satisfied with their postoperative pain management. ${ }^{1,2,3}$

Our study sought to determine whether there is a relationship between postoperative pain experienced by patients scheduled to elective surgery at a university hospital and their satisfaction with pain management.

\section{- Prospective observational study.}

- Ethics committee approval; Patient consent.

- Questionnaire administered to all patients undergoing elective inpatient surgery.

- 3 random non-consecutive days.

- Excluded: expected postoperative mechanical ventilation, psychiatric or neurologic disorder, patient refusal, day case procedures, cardiothoracic procedures.

- The pain at rest and dynamic pain were assessed at 4, 24 and 48 hours postoperatively, as well as the worst pain experienced in between, using a numeric scale from 0 (no pain) to 10 (worst pain imaginable).

- Patient satisfaction with their pain management was ascertained (using a Likert scale).

- Spearman correlation and Friedman test (with pairwise multiple comparisons).

86 of the 115 scheduled patients were enrolled in this study.

We found a statistical significant negative correlation between the level of pain (at rest, dynamic and worst pain experienced in between) at 24 and 48 hours postoperatively and patient satisfaction with pain management (rho $=-0,329$ to $-0,407, p<0,01$ ).

Interestingly, there was no significant correlation between de level of pain at 4 hours and satisfaction $(r=-0,059$ to $-1,56, p=0,151$ to 0,589$)$, despite the higher levels of pain at that time.

\begin{tabular}{|c|c|c|c|c|c|c|c|c|c|}
\hline \multicolumn{10}{|c|}{ Correlations with patient satisfaction } \\
\hline & \multicolumn{3}{|c|}{$4 \mathrm{~h}$} & \multicolumn{3}{|c|}{$24 \mathrm{~h}$} & \multicolumn{3}{|c|}{$48 \mathrm{~h}$} \\
\hline Pain & at rest & dynamic & worst till 4h & at rest & dynamic & $\begin{array}{c}\text { Worst from } \\
4 \mathrm{~h} \text { to } 24 \mathrm{~h}\end{array}$ & at rest & dynamic & $\begin{array}{l}\text { worst from } \\
24 \mathrm{~h} \text { till } 48 \mathrm{~h}\end{array}$ \\
\hline $\begin{array}{l}\text { Correlation } \\
\text { coefficient }\end{array}$ &,- 111 &,- 156 &,- 059 &,$- 329 *$ &,$- 330 *$ & $-378 *$ &,$- 407^{*}$ &,$- 370^{*}$ & $-340^{*}$ \\
\hline $\begin{array}{c}\text { Sig. } \\
\text { (2-tailed) }\end{array}$ & 310 & 151 & -589 & ,002 & , 002 & , 000 & , 000 & , 000 & , 001 \\
\hline
\end{tabular}

${ }^{*} \mathrm{p}<0,01$

The pain experienced at 24 and 48 hours postoperatively correlated with patient satisfaction with pain management. Early postoperative pain (at 4 hours postoperatively) did not influence patient satisfaction, although patients experienced higher levels of pain in this period of time.

If this results are due to patients' expectations in the early postoperative period is yet to be determined. 